\title{
Preparation of Ionic Conductivity Polymer Electrolyte Film Based on Epoxidized Deproteinized Natural Rubber
}

Nghiên cứu chế tạo màng điện phân polyme dẫn ion trên cơ sở cao su tự nhiên loại protein epoxy hóa

\author{
Trinh Thi Hang', Le Cao Chien', Bui Thi Thanh Binh', \\ Nguyen Thi Hong Phuong ${ }^{2}$, Seiichi Kawahara ${ }^{3}$, Phan Trung Nghia ${ }^{2 *}$ \\ ${ }^{1}$ Vietnam Institute for Building Materials, Hanoi, Vietnam \\ ${ }^{2}$ School of Chemical Engineering, Hanoi University of Science and Technology, Hanoi, Vietnam \\ ${ }^{3}$ Department of Materials Science and Technology, Nagaoka University of Technology, Japan \\ *Email: nghia.phantrung@hust.edu.vn
}

\begin{abstract}
lonic conductivity polymer electrolyte film based on epoxidized deproteinized natural rubber (EDPNR) and lithium salt lithium triflate $\left(\mathrm{LiCF}_{3} \mathrm{SO}_{3}\right)$ were prepared by solution casting technique. The EDPNR was prepared from deproteinized natural rubber latex (DNR) epoxidized in the latex stage with fresh peracetic acid $33 \%$, which was deproteinized by incubation of the latex with $0,1 \mathrm{wt} \%$ urea and $1 \mathrm{wt} \%$ surfactant. The ionic conductivity of EDPNR mixed with lithium salt was investigated through impedance analysis. The results show that the conductivity of EDPNR/ $\mathrm{LiCF}_{3} \mathrm{SO}_{3}$ mixture was dependent on $\mathrm{LiCF}_{3} \mathrm{SO}_{3} \mathrm{salt}$ concentration and amount of epoxy group. The highest ionic conductivity at room temperature obtained is $1,71 \times 10^{-5}{\mathrm{~S} . \mathrm{cm}^{-1}}^{-1} 35 \mathrm{wt} \% \mathrm{LiCF}_{3} \mathrm{SO}_{3}$ and $45 \mathrm{~mol} \%$ epoxy groups. Fourier transform infrared spectroscopy (FTIR) spectra showed evidence of complexation between EDPNR and $\mathrm{LiCF}_{3} \mathrm{SO}_{3}$. Glass transition temperature, $\mathrm{Tg}$ displayed an increasing trend in which are the increase in salt concentration and the increase in epoxy group concentration.
\end{abstract}

Keywords: Epoxidized deproteinized natural rubber, ionic conductivity polymer electrolyte.

Tóm tắt

Màng điện phân polyme dẫn ion trên cơ sở cao su tụ̣ nhiên loại protein epoxy hóa (EDPNR) và muối triflat $\left(\mathrm{LiCF}_{3} \mathrm{SO}_{3}\right)$ được chế tạo bằng phương pháp tạo màng dung dịch. Cao su tự nhiên loại protein (DPNR) thu được bằng cách ủ mủ cao su tự nhiên (NR) với 0,1\% khối lượng ure và 1\% khối lượng chất hoạt động bề mặt. Sau đó, sử dụng axit peraxetic mói điều chế 33\% epoxy hóa DPNR tạo ra sản phẩm EDPNR. Độ dẫn ion của EDPNR trộn với muối lithium được đánh giá bằng phương pháp tổng trở điện hóa, kết quả cho thấy độ dẫn ion của $E D P N R / L i \mathrm{CF}_{3} \mathrm{SO}_{3}$ phụ thuộc vào nồng độ muối và hàm lượng nhóm epoxy. Giá trị độ dẫn ion cao nhất đo tại nhiệt độ phòng $\sigma=1,71 \times 10^{-5} \mathrm{~S}_{\mathrm{cm}} \mathrm{cm}^{-1}$ tại $35 \%$ khối lượng $\mathrm{LiCF}_{3} \mathrm{SO}_{3}$ và $45 \%$ mol nhóm epoxy. Phổ FT-IR cho thấy có xảy ra quá trình tạo phức giữa $E D P N R$ và $\mathrm{LiCF}_{3} \mathrm{SO}_{3}$. Nhiệt độ hóa thủy tinh của $\mathrm{EDPNR} / \mathrm{LiCF}_{3} \mathrm{SO}_{3}$ tăng theo nồng độ muối và hàm lượng nhóm epoxy.

Từ khóa: Epoxidized deproteinized natural rubber, ion conductivity polymer electrolyte.

\section{Giới thiệu}

Màng điện phân polyme dẫn ion đang được tập trung nghiên cứu nhiều do tiềm năng ứng dụng trong các thiết bị điện hóa như pin, siêu tụ điện và các thiết bị điện hóa khác. Khi ứng dụng vào chế tạo pin lithium, màng điện phân polyme có ưu điểm hơn so với chất điện phân lỏng là không bị rò rỉ và không có vấn đề về cháy nổ. Sử dụng màng điện phân polyme dẫn ion không cần phải có một lớp màng phân cách. Màng điện phân polyme vừa có tác dụng dẫn ion vừa có nhiệm vụ làm màng phân cách giữa các điện cực trong pin lithium. Hơn nữa, màng điện phân polyme

ISSN: 2734-9381

https://doi.org/10.51316/jst.153.etsd.2021.31.4.12

Received: July 31, 2020; accepted: October 1, 2021 có độ bền cơ lý tốt và độ đàn hồi cao nên có thể chế tạo thành các kích thước và hình dạng mong muốn mà vẫn đảm bảo tính chất cơ học của màng. Nhược điểm chính của chất điện phân polyme là có độ dần thấp hơn chất điện phân lỏng [1]. Chất điện phân polyme lý tưởng nhất phải có độ dẫn ion của chất lỏng và độ ổn định cơ học của chất rắn.

Những nghiên cứu đầu tiên về chất điện phân polyme chủ trên cơ sở polyethylene oxide (PEO) kết hợp với các muối lithium vô cơ khác nhau. Tuy nhiên, chất điện phân trên cơ sở vật liệu nền PEO có độ dẫn thấp khoảng $10^{-7}$ to $10^{-6} \mathrm{~S} \mathrm{~cm}^{-1}$ ở nhiệt độ phòng nên hạn chế khả năng ứng dụng thực tế. 
Những hạn chế của chất điện phân trên cơ sở PEO đã được các nhà nghiên cứu khắc phục bằng cách sử dụng các polyme nền có chứa các nhóm phân cực khác như polyacrylonitril (PAN) [2], PMMA [3], để nghiên cứu sử dụng làm vật liệu nền trong chất điện phân.

Trong những năm gần đây, các polyme tự nhiên như chitosan [4], tinh bột [5] và cao su tự nhiên [6] sau khi biến tính cũng đã được nghiên cứu nhiều do polyme tự nhiên thân thiện môi trường, không độc hại, sẵn có, giá thành thấp. Cao su tự nhiên epoxy hóa (ENR) là một polyme có cấu trúc vô định hình, nhiệt độ hóa thủy tinh $(T g)$ thấp và có độ đàn hồi tốt. Trong cấu trúc polyme có chứa các nhóm epoxy là nhóm phân cực có khả năng tạo phức với các ion $\mathrm{Li}^{+}$nên phù hợp để làm polyme nền trong màng điện phân. Tuy nhiên qua các nghiên cứu trước đây đã chế tạo màng polyme điện phân từ ENR thương mại (ENR50) nhận thấy độ dẫn tăng tuyến tính theo hàm lượng muối [7] điều này xảy ra khi màng bị hấp thụ nước [8]. Hiện tượng nước bị hấp thụ vào màng điện phân ENR có thể cho rằng do $\mathrm{ENR}$ có chứa lượng protein hơn $2 \%$, chất này hấp thụ nước nên gây ra hiện tượng tăng độ dẫn đơn điệu theo hàm lượng muối. Tại Việt Nam, cao su tự nhiên (NR) là nguồn nguyên liệu có ý nghĩa kinh tế và kỹ thuật quan trọng. Tuy nhiên, so với các nước khác trong khu vực, trình độ công nghệ chế biến cao su nước ta còn lạc hậu, trang thiết bị nghèo nàn, không đồng bộ, vì vậy chủng loại các mặt hàng cao su còn ít, đơn điệu và phần lớn các loại cao su kỹ thuật vẫn phải nhập khẩu trong khi nhu cầu sử dụng trong các ngành công nghiệp sản xuất là rất lớn. Sử dụng cao su thiên nhiên để tổng hợp màng điện phân có nhiều ưu điểm như: giá thành thấp, độ đàn hồi của vật liệu polyme cao dẫn tới khả năng tiểp xúc giữa vật liệu với các điện cực tốt, thân thiện môi trường. Trong nghiên cứu này, sử dụng cao su tự nhiên ở Việt Nam, loại bỏ protein trước khi tiến hành quá trình epoxy hóa để tạo ra các sản phẩm cao su tự nhiên loại protein epoxy hóa. Sau đó nghiên cứu chế tạo màng điện phân trên cơ sở EDPNR có hàm lượng nhóm epoxy khác nhau kết hợp muối $\mathrm{LiCF}_{3} \mathrm{SO}_{3}$.

\section{Thực nghiệm}

\subsection{Chuẩn bị mẫu}

Mủ cao su thương mại của Công ty TNHH MTV Cao su Dầu Tiếng, Tập đoàn Công nghiệp Cao su Việt Nam, được sử dụng trong nghiên cứu là mủ cao su có hàm lượng ammoniac cao (High Ammoniac Natural Rubber - HANR). Quá trình loại protein từ cao su được thực hiện bằng cách ủ mủ cao su có hàm lượng rắn (DRC) $30 \%$ khối lượng với $0,1 \%$ khối lượng ure (Nacalai Tesque-Nhật Bản) và $1 \%$ khối lượng sodium dodecyl sulfate (SDS) trong 60 phút sau đó tiến hành quay ly tâm. Phần rắn thu được hòa vào trong dung dịch $\operatorname{SDS} 1 \%$ khối lượng và được rửa 3 lần bằng cách quay ly tâm. DPNR (DRC $10 \%$ khối lượng) được điều chỉnh $\mathrm{pH}=5-6$ bằng axit axetic, làm lạnh ở $10^{\circ} \mathrm{C}$, sau đó tiến hành quá trình epoxy hóa mủ DPNR với axit peraxetic $33 \%$ ở các thể tích khác nhau $(20 \mathrm{~mL}, 30 \mathrm{~mL}, 40 \mathrm{~mL}, 50 \mathrm{~mL}, 60 \mathrm{~mL})$ trong 3 giờ ở nhiệt độ $10^{\circ} \mathrm{C}$ tao ra mủ EDPNR. Sau khi hoàn thành phản ứng, $\mathrm{pH}$ được điều chỉnh về 7,1 bằng $\mathrm{NaHCO}_{3}$ và mủ EDPNR được đông tụ lại bằng cách thêm $\mathrm{CH}_{3} \mathrm{OH}$. Sau đó, sản phẩm được rửa nhiều lần bằng nước và sấy khô tại nhiệt độ phòng trong điều kiện chân không. Sản phẩm EDPNR tạo thành được hòa tan trong tetrahydrofuran THF trong 24 giờ, sau đó phân tán muối $\mathrm{LiCF}_{3} \mathrm{SO}_{3} 99 \%$ (Aldrich) vào hỗn hợp này và tiếp tục khuấy trong khoảng 72 giờ. Hỗn hợp đồng nhất được rót vào đĩa petri đã được dính băng dính polytetrafloetylen và làm khô chậm để tạo thành màng ở nhiệt độ phòng. Màng này tiếp tục được làm khô thêm trong tủ sấy chân không trong 48 giờ ở nhiệt độ $40^{\circ} \mathrm{C}$ để loại bỏ hết các phần dung môi còn sót lại trong màng. Sản phẩm màng điện phân polyme tạo thành được lưu giữ trong bình cách ẩm.

\subsection{Các phương pháp phân tích}

Hàm lượng nitơ tổng được xác định bằng phương pháp Kjeldahl (ISO 1656: 1996) và hàm lượng epoxy được xác định bằng phương pháp phân tích FTIR. Từ phổ FTIR, tỷ lệ hấp thụ tương đối được tính toán theo công thức [9]:

$$
A \mathrm{r}=a \_870 /\left(\left(a \_835+a \_870\right)\right)
$$

trong đó: $a \_870$ là độ hấp thụ tại số sóng $870 \mathrm{~cm}^{-1} \mathrm{do}$ nhóm epoxy và $a \_835$ là độ hấp thụ tại số sóng $835 \mathrm{~cm}^{-1}$ do nhóm $\overline{\mathrm{C}}=\mathrm{C}$ của cis-1,4 polyisopren.

Sau đó, hàm lượng nhóm epoxy trong EDPNR được tính toán bằng cách sử dụng đường chuẩn $\mathrm{Ar}$ [9]. Sử dụng phương pháp phân tích nhiệt DSC để xác định nhiệt độ hóa thủy tinh của DPNR, EDPNR và các màng điện phân polyme trên cơ sở EDPNR. Các mẫu được đo trên máy Seiko Instrument DSC $220 \mathrm{C}$, gia nhiệt từ $-100 \mathrm{C}$ đến $100 \mathrm{C}$ với tốc độ gia nhiệt $10 \mathrm{C} /$ phút. Độ dẫn của màng điện phân được xác định từ giá trị điện trở thu được qua phương pháp tổng trở điện hóa. Màng điện phân có chiều dày khoảng $0,02 \quad 0,03 \mathrm{~cm}$ kẹp giữa hai điện cực thép không rỉ có đường kính $1 \mathrm{~cm}$ và được đo bằng máy đo điện hóa Biologic VSP 300. Giá trị độ dẫn ion $(\sigma)$ được xác định bằng công thức sau:

$$
\sigma=\frac{L}{R_{b} A}
$$

trong đó: $\sigma$ là độ dẫn ion $\left(\mathrm{S} . \mathrm{cm}^{-1}\right) ; L$ là chiều dày màng $(\mathrm{cm}) ; A$ là diện tích tiếp xúc của mẫu với điện cực $\left(\mathrm{cm}^{2}\right) ; R_{b}$ là giá trị đo được $(\Omega)$

\section{Kết quả và thảo luận}

\section{1. Ảnh hưởng của hàm lựng ure đến hiệu quả tách loại Protein}


Ure có thể tương tác với protein dẫn tới làm thay đổi cấu trúc protein [16]. Do vậy, có thể loại bỏ protein khỏi cao su hiệu quả, đơn giản bằng cách sử dụng ure.

Bảng 1. Ảnh hưởng của hàm lượng Ure đến hiệu quả loại protein

\begin{tabular}{|l|c|c|c|c|c|}
\hline \multirow{2}{*}{$\begin{array}{c}\text { Hàm } \\
\text { lượn }\end{array}$} & \multicolumn{5}{|c|}{ Hàm lượng nitơ tổng (\%) } \\
\cline { 3 - 6 } $\begin{array}{c}\text { Ure } \\
(\%)\end{array}$ & HANR & \multicolumn{4}{|c|}{ Ly tâm } \\
\cline { 3 - 6 } & & Lần 1 & Lần 2 & Lần 3 & Lần 4 \\
\hline 0,04 & 0,306 & 0,0790 & 0,0358 & 0,0043 & 0,0043 \\
\hline 0,10 & 0,306 & 0,0689 & 0,0272 & 0,0028 & 0,0028 \\
\hline 0,16 & 0,306 & 0,0892 & 0,0576 & 0,0067 & 0,0067 \\
\hline 0,22 & 0,306 & 0,1123 & 0,0987 & 0,0123 & 0,0123 \\
\hline
\end{tabular}

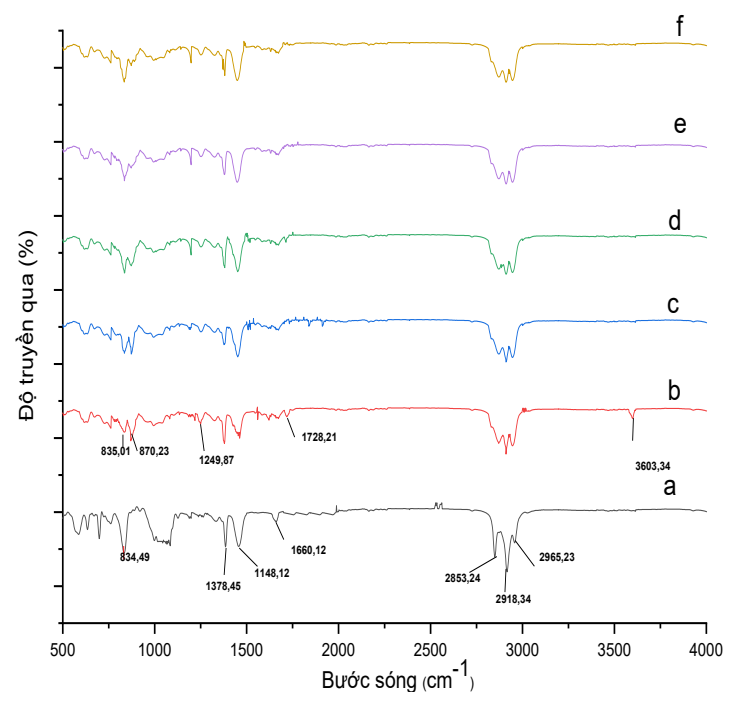

Hình 1. Phổ FTIR của các mẫu DPNR và EDPNR

a, Cao su tự nhiên loại protein

b, DPNR epoxy hóa ở hàm lượng axit $60 \mathrm{~mL}$

c, DPNR epoxy hóa ở hàm lượng axit $50 \mathrm{~mL}$

d, DPNR epoxy hóa ở hàm lượng axit $40 \mathrm{~mL}$

e, DPNR epoxy hóa ở hàm lượng axit $30 \mathrm{~mL}$

f, DPNR epoxy hóa ở hàm lượng axit $20 \mathrm{~mL}$

Trong nghiên cứu này, nhóm nghiên cứu đã tiến hành khảo sát ảnh hưởng của hàm lượng ure đến hiệu quả loại bỏ protein và xác định hàm lượng nitơ trong sản phẩm thu được bằng phương pháp Kjeldahl (ISO 1656: 1996), kết quả như trong Bảng 1 . Kết quả cho thấy: khi sử dụng ure $0,1 \%$ khối lượng hàm lượng nitơ trong cao su giảm nhiều nhất còn $0,0028 \%$.

3.2. Änh hưởng của hàm lựng axit peraxetic $33 \%$ khối lự̛ng đến hàm lự̛ng nhóm epoxy
Nhóm nghiên cứu đã tiến hành epoxy hóa DPNR với axit peraxetic $33 \%$ với thể tích axit thay đổi $20 \mathrm{~mL}, 30 \mathrm{~mL}, 40 \mathrm{~mL}, 50 \mathrm{~mL}, 60 \mathrm{~mL}$. Sản phẩm thu được tiến hành phân tích qua phổ FT-IR, kết quả thu được như Hình 1. Phổ FTIR của DPNR và EDPNR có xuất hiện peak hấp thụ giống nhau tại bước sóng $834,49 \mathrm{~cm}^{-1}$ đặc trưng cho liên kết $\mathrm{C}=\mathrm{C}$ của isopren, peak hấp thụ tại bước sóng $1660 \mathrm{~cm}^{-1}$ đặc trưng cho liên kết $\mathrm{C}=\mathrm{C}$, peak hấp thụ tại bước sóng $1378,45 \mathrm{~cm}^{-1}$ và $1448,12 \mathrm{~cm}^{-1}$ là các peak đặc trưng cho dao động của các nhóm $\mathrm{CH}_{3}$ và $\mathrm{CH}_{2}$ [10]. Các peak hấp thụ tại bước sóng $2853,24 \mathrm{~cm}^{-1}$ và $2918,34 \mathrm{~cm}^{-1}$ và $2965,23 \mathrm{~cm}^{-1}$ là các peak đăc trưng cho các dao động giãn đối xứng của $-\mathrm{CH}_{2}$, dao động không đối xứng $-\mathrm{CH}_{3}$ và dao động kéo giãn của $=\mathrm{CH}$ [11]. Đối với phổ FTIR của EDPNR nhận thấy xuất hiện thêm các đỉnh peak hấp thụ tại các vùng bước sóng khoảng $870 \mathrm{~cm}^{-1}$ và $1249,87 \mathrm{~cm}^{-1}$. Đây là các peak đặc trưng hấp thụ của nhóm epoxy $[9,12]$.

Qua kết quả phân tích phổ FTIR của các mẫu EDPNR với hàm lượng axit sử dụng trong quá trình epoxy hóa khác nhau cho thấy tín hiệu peak thu được tại vùng bước sóng $835 \mathrm{~cm}^{-1}$ và $870 \mathrm{~cm}^{-1}$ có cường độ hấp thụ khác nhau. Cường độ hấp thụ của các peak này tăng khi hàm lượng axit peraxetic sử dụng tăng và trên phổ của EDPNR nhận thấy cường độ hấp thụ của các peak ở vùng bước sóng $835 \mathrm{~cm}^{-1}$ và $1660 \mathrm{~cm}^{-}$ ${ }^{1}$ giảm dần khi hàm lượng acid sử dụng tăng. Hàm lượng nhóm epoxy được xác định bằng cách sử dụng công thức (1) và sử dụng đường chuẩn trong tài liệu [9]. Kết quả nhận được hàm lượng nhóm epoxy thay đổi theo hàm lượng axit sử dụng như Hình 2.

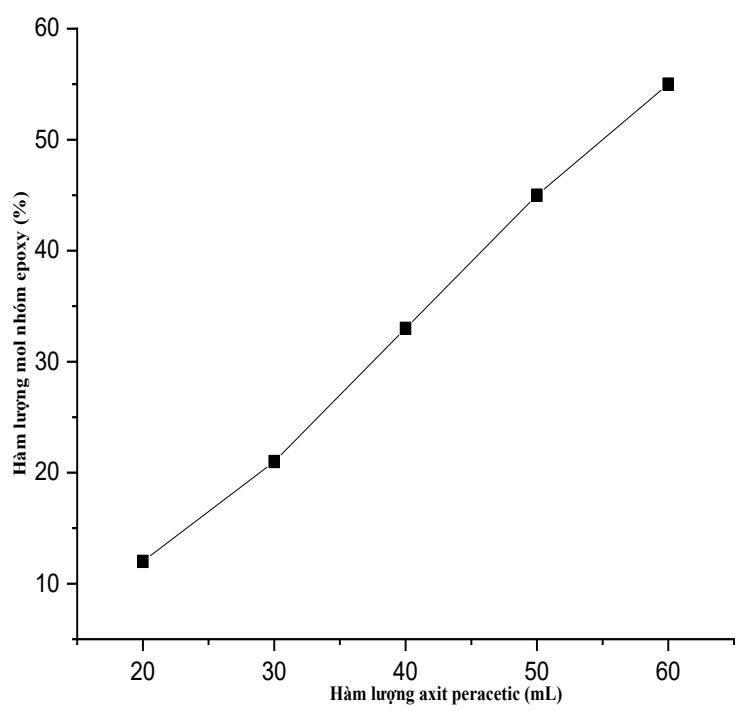

Hình 2. Ảnh hưởng của hàm lượng axit peracetic đến hàm lượng nhóm epoxy

Từ kết quả trình Hình 2, nhận thấy trong cùng điều kiện thời gian và nhiệt độ phản ứng, hàm lượng axit sử dụng đề epoxy hóa DPNR tăng thì hàm lượng nhóm epoxy tạo thành tăng. Hàm lượng nhóm epoxy thu được là $12,21,33,45,55 \%$ mol tương ứng với 
hàm lượng axit sử dụng $20 \mathrm{~mL}, 30 \mathrm{~mL}, 40 \mathrm{~mL}$, $50 \mathrm{~mL}, 60 \mathrm{~mL}$. Tuy nhiên, khi hàm lượng axit sử dụng cao thì có thể xảy ra phản ứng mở vòng nhóm epoxy, điều này được thể hiện trên phổ phân tích FTIR (Hình 1) có xuất hiện 2 peak tại vùng bước sóng $1728 \mathrm{~cm}^{-1}$ và $3603 \mathrm{~cm}^{-1}$. Các peak này có thể là các peak đặc trưng cho nhóm este tạo thành do sự hình thành nhóm hydroxyl từ phản ứng mở vòng nhóm epoxy dẫn tới tạo các nhóm este trong quá trình epoxy hóa cao su ở hàm lượng axit sử dụng cao [9].

\subsection{Nghiên cứu ảnh hưởng của hàm lượng axit peraxetic đến nhiệt độ hóa thủy tinh của cao su tụ nhiên loại protein epoxy hóa}

Polyme nền sử dụng trong màng điện phân polyme cần phải có nhiệt độ hóa thủy tinh thấp, giá trị $T g$ thấp giúp cho các đại phân tử có độ linh hoạt cao tại nhiệt độ môi trường cho phép quá trình vận chuyển các ion trong hệ điện phân tốt hơn. Quá trình epoxy hóa cao su tự nhiên nhằm đưa các nhóm epoxy phân cực vào mạng nền polyme để tạo phức với các muối kim loại, tạo ra đường dẫn ion trong nền polyme. Tuy nhiên, quá trình epoxy hóa cũng làm tăng $T g$ của mạng cao su lên. Khi mức độ epoxy hóa tăng, giá trị $T g$ tăng lên khoảng $1 \mathrm{C}$ khi tăng $1 \%$ mol nhóm epoxy của ENR. Đã tiến hành kiểm tra nhiệt độ hóa thủy tinh của các sản phẩm epoxy hóa tạo thành và cao su tự nhiên loại bỏ protein bằng phương pháp DSC, kết quả thu được thể hiện trên Hình 3.

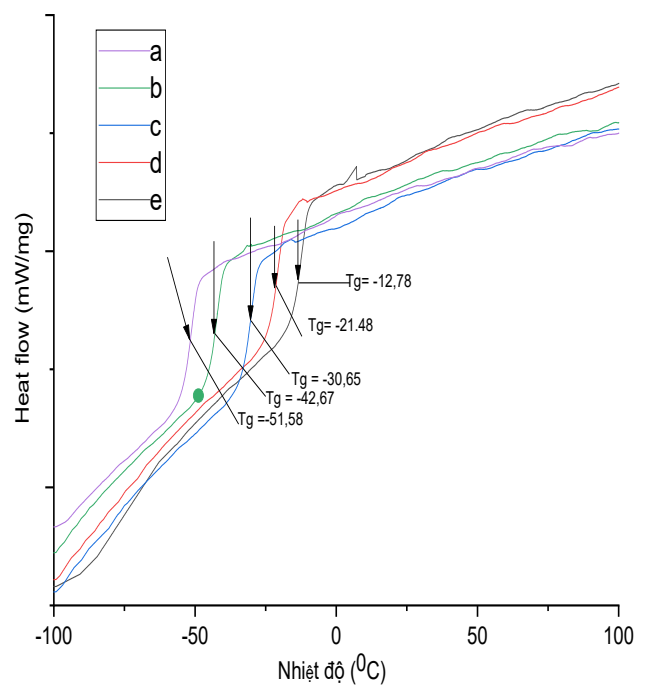

Hình 3. Giản đồ phân tích DSC của EDPNR

(a) DPNR epoxy hóa ở lượng acid peraxetic $20 \mathrm{~mL}$

(b) DPNR epoxy hóa ở lượng acid peraxetic $30 \mathrm{~mL}$

(c) DPNR epoxy hóa ở lượng acid peraxetic $40 \mathrm{~mL}$

(d) DPNR epoxy hóa ở lượng acid peraxetic $50 \mathrm{~mL}$

(e) DPNR epoxy hóa ở lượng acid peraxetic $60 \mathrm{~mL}$
Từ Hình 3 nhận thấy: nhiệt độ hóa thủy tinh của các sản phẩm EDPNR tăng từ $-51,58^{\circ} \mathrm{C}$ đến $-12,78^{\circ} \mathrm{C}$ tương ứng với hàm lượng axit peraxetic sử dụng tăng từ $20 \mathrm{~mL}$ đến $60 \mathrm{~mL}$. Kết quả này cho thấy các sản phẩm EDPNR đều có $T g$ thấp (ở vùng nhiệt độ âm) nên tại nhiệt độ phòng các sản phẩm này đều có tính chất đàn hồi tốt phù hợp sử dụng để làm polyme nền trong màng điện phân polyme.

\subsection{Nghiên cúu chế tạo màng điện phân trên cơ sở EDPNR và $\mathrm{LiCF}_{3} \mathrm{SO}_{3}$}

3.4.1 Anh huởng của hàm lương muối đến tính chất của màng điện phân

Để nghiên cứu ảnh hưởng của hàm lượng $\mathrm{LiCF}_{3} \mathrm{SO}_{3}$ đến tính chất của màng điện phân. Nhóm nghiên cứu đã tiến hành chế tạo màng điện phân trên cơ sở EDPNR45 (hàm lượng nhóm epoxy 45\% mol) và $\mathrm{LiCF}_{3} \mathrm{SO}_{3}$ ở các hàm lượng muối khác nhau. Sau đó tiến hành đo giá trị độ dẫn của màng, kết quả thể hiện ra như Hình 4.

Từ kết quả trên Hình 4 nhận thấy độ dẫn của màng EDPNR45 thấp khoảng $1,74 \times 10^{-10}{\mathrm{~S} . \mathrm{cm}^{-1}}^{-1 a ̣ i}$ nhiệt độ phòng. Khi trộn muối lithium vào EDPNR45, độ dẫn ion của màng tăng khi tăng hàm lượng muối lithium sử dụng và đạt giá trị độ dẫn cao nhất là $1,71 \times 10^{-5} \mathrm{~S} . c m^{-1}$ tại hàm lượng muối lithium $35 \%$ khối lượng. Khi hàm lượng muối lớn hơn $35 \%$ khối lượng, độ dẫn màng điện phân giảm khi hàm lượng muối tăng. Muối lithium cung cấp các ion $\mathrm{Li}^{+}$ tạo ra dòng dẫn ion. Độ dẫn tăng khi hàm lượng muối tăng đến $35 \%$ khối lượng là do khi tăng hàm lượng muối vào màng điện phân sẽ tăng số ion $\mathrm{Li}^{+}$linh động trong màng. Ở nồng độ muối thấp, độ dẫn ion bị ảnh hưởng mạnh bởi số lượng hạt mang điện tích và tính linh động của các ion không bị ảnh hưởng nhiều.

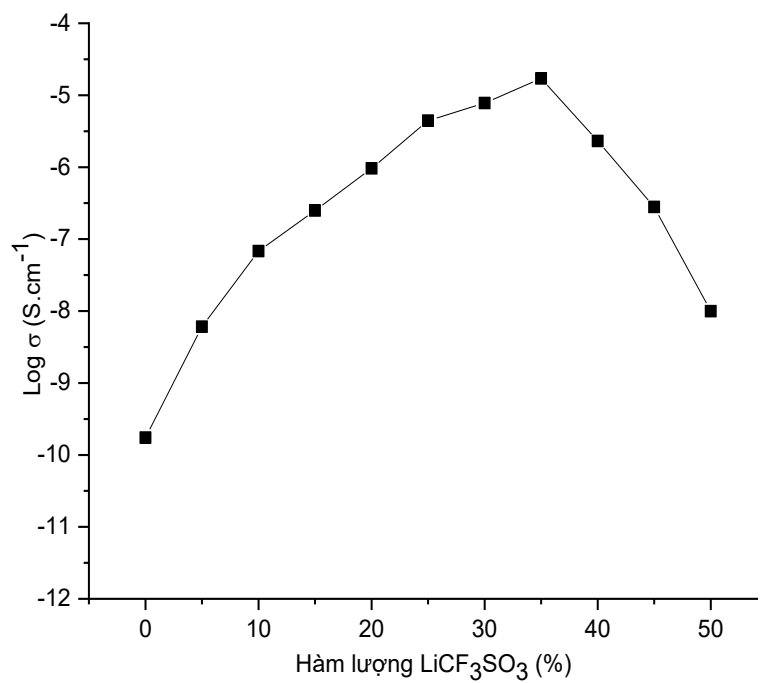

Hình 4. Ảnh hưởng của hàm lượng muối đến tính chất dẫn của màng EDPNR45 
Tuy nhiên, khi hàm lượng muối lớn hơn 35\% khối lượng, độ dẫn ion phụ thuộc nhiều vào độ linh động của các ion và đường dần ion. Quá trình $\mathrm{di}$ chuyển ion có liên quan chặt chẽ tới chuyển động của các phân đoạn polyme. Nhóm nghiên cứu đã phân tích DSC các sản phẩm này để xác định nhiệt độ $T g$, kết quả thu được như trên Hình 5.

Từ Hình 5 nhận thấy nhiệt độ hóa thủy tinh tăng khi hàm lượng muối sử dụng tăng. Điều này là do sự hình thành các liên kết ngang tạm thời bằng liên kết phối trí nội phân tử và liên phân tử của nguyên tử ôxi trong EDPNR với $\mathrm{Li}^{+}$hạn chế độ linh động phân đoạn của mạch EDPNR dẫn tới tăng giá trị $T g$.

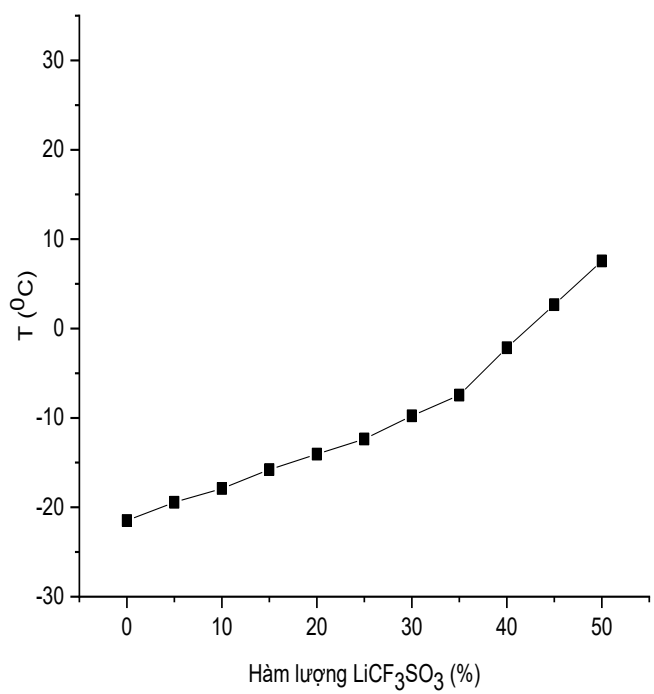

Hình 5. Ảnh hưởng của hàm lượng muối đến $T g$
Giá trị $T g$ tăng dần với hàm lượng muối sử dụng cho đến khi hàm lượng muối sử dụng lớn hơn $35 \%$ khối lượng, giá trị $T g$ tăng mạnh từ giá trị $T g=-7,45^{\circ} \mathrm{C}$ tại $35 \%$ khối lượng $\mathrm{LiCF}_{3} \mathrm{SO}_{3}$ lên giá trị $T g=-2,15^{\circ} \mathrm{C}$ tại $40 \%$ khối lượng $\mathrm{LiCF}_{3} \mathrm{SO}_{3}$. Kết quả cho thấy các liên kết ngang tạm đủ nhiều làm ngăn cản chuyển động của các phân đoạn polyme dẫn tới tốc độ tăng $T g$ cao và độ dẫn của màng giảm khi hàm lượng muối sử dụng nhiều hơn $3 \%$. Các nghiên cứu trước đây đã cho rằng trên nồng độ muối nhất định, tốc độ tăng $T g$ cao do mức độ tạo liên kết ngang nhiều làm giảm độ linh động của chuỗi polyme và khi đó sự phân bố muối trở nên không đồng nhất [13].

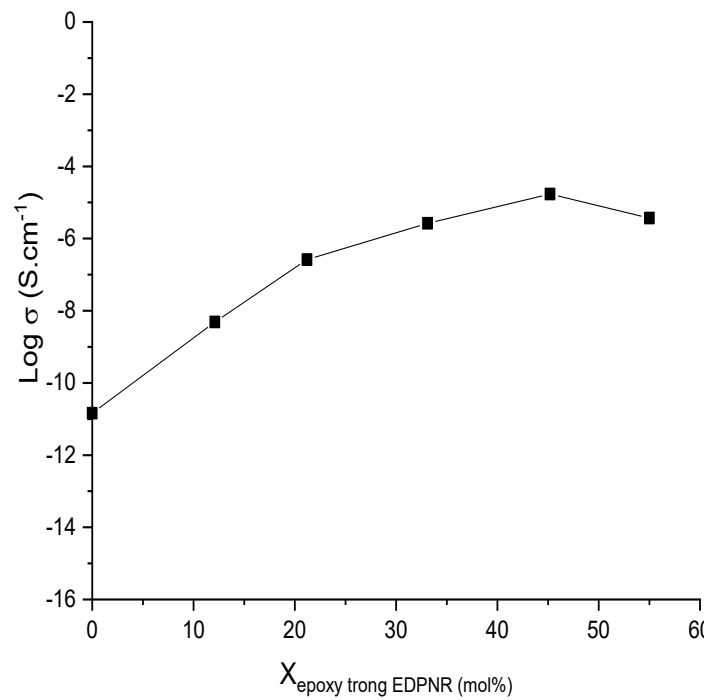

Hình 6. Ảnh hưởng của hàm lượng nhóm epoxy đến độ dẫn ion của hệ màng điện phân

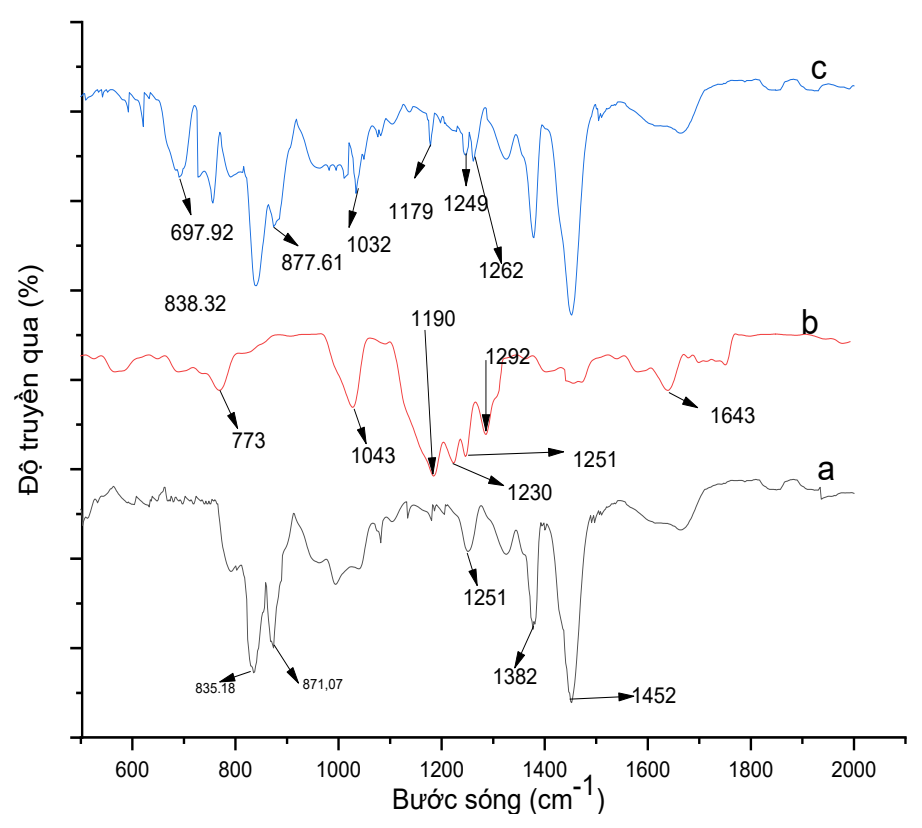

Hình 7. Phân tích phổ FT-IR
a, EDPNR45
b, Muối $\mathrm{LiCF}_{3} \mathrm{SO}_{3}$
c, Hệ màng điện phân EDPNR45 và $\mathrm{LiCF}_{3} \mathrm{SO}_{3}$ 
3.4.2 Anh hưởng của hàm luợng nhóm epoxy đến tích chất của màng điện phân

Từ các kết quả nghiên cứu trên nhận thấy màng điện phân trên cơ sở EDPNR45 và muối $\mathrm{LiCF}_{3} \mathrm{SO}_{3}$ có độ dẫn cao nhất tại hàm lượng muối sử dụng là $35 \%$ khối lượng. Nhóm nghiên cứu lựa chọn hàm lượng muối này để nghiên cứu ảnh hưởng của hàm lượng nhóm epoxy đển tính chất dẫn của màng điện phân, kết quả độ dẫn ion thu được như Hình 6.

Kết quả trên Hình 6 cho thấy khi hàm lượng nhóm epoxy tăng thì độ dẫn của màng tăng và đạt giá trị lớn nhất tại hàm lượng nhóm epoxy $45 \%$ mol. Sau đó, độ dẫn màng giảm ở hàm lương nhóm epoxy $55 \%$ mol. Điều này có thể cho rằng khi hàm lượng nhóm epoxy cao (EDPNR55), mạch cao su có nhiều vị trí phân cực dẫn tới tăng giá trị $T g$ của màng điện phân và cản trở chuyển động của các phân đoạn của EDPNR dẫn tới giảm độ dẫn.

\subsubsection{Anh hưởng của $\mathrm{LiCF}_{3} \mathrm{SO}_{3}$ đến cấu trúc hóa học của màng điện phân trên co sở EDPNR}

Sử dụng phương pháp phân tích FTIR để phân tích các tương tác liên phân tử xảy ra giữa polyme và muối. Nhóm nghiên cứu tập trung phân tích các dao động của màng điện phân trên cơ sở EDPNR45 và muối lithium sử dụng ở hàm lượng $35 \%$ khối lượng trong phạm vi bước sóng từ $2000 \mathrm{~cm}^{-1}$ dến $500 \mathrm{~cm}^{-1}$. Từ các tài liệu tham khảo được nhận thấy các liên kết phối trí giữa $\mathrm{Li}$ và $\mathrm{O}$ thường ở tần số dao động bước sóng thấp từ $600-720 \mathrm{~cm}^{-1}$ và các dao động liên kết của nhóm epoxy trong cao su tự nhiên epoxy như phân tích ở phần trên nằm trong dải bước sóng nhỏ hơn $2000 \mathrm{~cm}^{-1}$. Kêt quả phân tích phổ FTIR của các mẫu như trên Hình 7.

Từ kết quả trên Hình $7 \mathrm{~b}$ nhận thấy các peak hấp thụ tại bước sóng $773,12 \mathrm{~cm}^{-1}, 1190 \mathrm{~cm}^{-1}$ và $1251 \mathrm{~cm}^{-1}$ tương ứng với các đặc trưng dao động biến dạng đối xứng $\delta\left(\mathrm{CF}_{3}\right)$, dao động giãn bất đối xứng $v_{\mathrm{a}}\left(\mathrm{CF}_{3}\right)$ và dao động giãn đối xứng $v_{\mathrm{s}}\left(\mathrm{CF}_{3}\right)$. Peak hấp thụ tại bước sóng $1043 \mathrm{~cm}^{-1}$ và $1251 \mathrm{~cm}^{-1}$ là các dao động giãn đối xứng $v_{\mathrm{s}}\left(\mathrm{SO}_{3}\right)$ và không đối xứng $v_{\mathrm{a}}\left(\mathrm{SO}_{3}\right)$ [14]. Kết quả trên Hình 7c cho thấy peak dao động của nhóm epoxy trong EDPNR45 tại bước sóng hấp thụ $1251 \mathrm{~cm}^{-1}$ (Hình 7a) đã được thay thế bằng 2 đỉnh peak hấp thụ tại vùng bước sóng này trong hệ màng điện phân EDPNR45 và $\mathrm{LiCF}_{3} \mathrm{SO}_{3}$. Ngoài ra, xuất hiện 2 đỉnh peak mới tại $1179 \mathrm{~cm}^{-1}$ và $1032 \mathrm{~cm}^{-1}$ có thể đây là peak hấp thụ của các cặp ion và ion tự do. Peak hấp thụ tại bước sóng 697,92 $\mathrm{cm}^{-1}$ đặc trưng dao động đối xứng của $v_{\mathrm{s}}\left(\mathrm{LiO}_{2}\right)$ [15], peak này cho thấy muối được hòa tan trong EDPNR45 tạo ra liên kết phối trí giữa ion $\mathrm{Li}^{+}$và oxy trong nhóm epoxy. Những peak khác ở bước sóng $835,18 \mathrm{~cm}^{-1} \quad 871,07 \mathrm{~cm}^{-1}, 1382 \mathrm{~cm}^{-1}$ và $1452 \mathrm{~cm}^{-1}$ của EDPNR45 có sự thay đổi không đáng kể trong màng điện phân EDPNR45 và $\mathrm{LiCF}_{3} \mathrm{SO}_{3}$. Từ kết quả trên cho thây khi thêm muối vào mạng nền polyme đã tạo ra các peak hấp thụ mới và một số peak dịch chuyển, do đó có thể kết luận rằng đã xảy ra tương tác giữa $\mathrm{LiCF}_{3} \mathrm{SO}_{3}$ và EDPNR45.

\section{Kết luận}

Đã tiến hành giảm được hàm lượng protein trong $\mathrm{NR}$ bằng ure $0,1 \%$ xuống còn $0,0028 \%$ sau 3 lần quay ly tâm. Sau đó tiến hành quá trình epoxy hóa DPNR thu được EDPNR có hàm lượng nhóm epoxy khác nhau, giá trị $T g$ của EDPNR tăng theo hàm lượng nhóm epoxy ( $T g$ tăng từ 51,58 đến $-12,78{ }^{\circ} \mathrm{C}$ tương ứng với hàm lượng nhóm epoxy trong EDPNR tăng từ 12 đến $55 \% \mathrm{~mol}$ ). Màng điện phân trên cơ sở EDPNR và $\mathrm{LiCF}_{3} \mathrm{SO}_{3}$ có giá trị độ dẫn thay đổi theo hàm lượng nhóm epoxy và hàm lượng muối lithium. Giá trị độ dẫn cao nhất đo tại nhiệt độ phòng $\sigma=1,71 \times 10^{-5} \mathrm{~S} \mathrm{~cm}^{-1}$ khi sử dụng EDPNR45 kết hợp với $35 \%$ khối lượng muối $\mathrm{LiCF}_{3} \mathrm{SO}_{3}$. $\mathrm{Tg}$ của màng điện phân tăng theo hàm lượng muối sử dụng. Phổ IR của EDPNR45 và $\mathrm{LiCF}_{3} \mathrm{SO}_{3}$ cho thấy các peak có sự dịch chuyển và xuất hiện peak tạo phức Li và oxi tại bước sóng bước sóng 697,92 $\mathrm{cm}^{-1}$.

\section{Lời cám ơn}

Nghiên cứu này được tài trợ bởi Quỹ phát triển khoa học và công nghệ quốc gia Việt Nam (NAFOSTED) theo Grant no. 104.02-2016.47.

\section{Tài liệu tham khảo}

[1] $\mathrm{Xu}, \mathrm{K}$., Nonaqueous liquid electrolytes for lithiumbased rechargeable batteries, Chemical Reviews, 4303-4417 (2004).

https://doi.org/10.1021/cr030203g

[2] M.A.K.L. Dissanayake, L.R.A.K.B. .Bandara, R.S.P. Bokalawala, P.A.R.D. Jayathilaka, O.A. Ileperuma, S. Somasundaram, A novel gel polymer electrolyte based on polyacrylonitrile (PAN) and its application in a solar cell, Materials Research Bulletin, 867 - 874 (2002).

https://doi.org/10.1016/S0025-5408(02)00712-2

[3] C. Nakason, Y.P., A. Kaesaman, Rheological and thermal properties of thermoplastic natural rubbers based on poly (methyl methacrylate)/ epoxidizednatural-rubber blends, Journal of Applied Polymer Science 3561-3572 (2004). https://doi.org/10.1002/app.20384

[4] M. H. Buraidah, L.P.Teo, S.R.Majid, R.Yahya, R.M.Taha, A.K.Arof, Characterizations of chitosanbased polymer electrolyte photovoltaic cells, International Journal of Photoenergy, 1-7 (2010). https://doi.org/10.1155/2010/805836

[5] R.I. Mattos, C.E.T., J.P. Donoso, A. Pawlicka, NMR study of starch based polymer gel electrolytes: humidity effects, Electrochimica Acta, 1461-1465 (2007).

https://doi.org/10.1016/j.electacta.2007.05.061

[6] A. Ahmad, M.Y.A.R Rahman., M. L. M. Ali, H. Hashim F. A. Kalam, Solid polymeric electrolyte of PVC-ENR-LiClO4, Ionics, 67-70 (2007). https://doi.org/10.1007/s11581-007-0074-2 
[7] Razali Idris, M.D.G., R.J. Latham*, R.G. Linford, W.S. Schlindwein, Polymer electrolytes based on modified natural rubber for use in rechargeable lithium batteries, Journal of Power Sources 206-211 (2001).

https://doi.org/10.1016/S0378-7753(00)00588-7

[8] Asa Lauenstein, A.J., and Jörgen Tegenfeldt, Water absorption of the polymer electrolyte systems $\mathrm{Pb}(\mathrm{CF} 3 \mathrm{SO} 3) 2 \mathrm{PEO}$. and $\mathrm{Zn}(\mathrm{CF} 3 \mathrm{SO} 3) 2 \mathrm{PEO}$, Journal of the Electrochemical Society, 1819-1823 (1994). https://doi.org/10.1149/1.2055010

[9] Loadman, J.E.D.a.M.J.R., A chemical demonstration of the randomness of epoxidation of natural rubber. British Polyme Journal, 134-138 (1984). https://doi.org/10.1002/pi.4980160305

[10] Zeng Zong-Qiang, Y.H.-P., Wang Qi-Fang, Lu Guang, Effects of coagulation processes on properties of epoxidized natural rubber, Journal of Applied Polymer Science, 1944-1949 (2008). https://doi.org/10.1002/app.28119

[11] Suhawati Ibrahim, R.D., Ibrahim Abdullah, Functionalization of liquid natural rubber via oxidative degradation of natural rubber, Polymers 2928-2941 (2014) https://doi.org/10.3390/polym6122928

[12] N A Kinasih, M.I.F., D A Winarto, Swelling behaviour in n-pentane and mechanical properties of epoxidized natural rubber with different epoxide content, Innovation in Polymer Science and Technology, Proc. in IOP Conf. Ser., Mater. Sci. Eng. Vol. 223, 012002, 2017. https://doi.org/10.1088/1757-899X/223/1/012002

[13] Jean-Francois Le Nest, A.G., Herve cheradame, crosslinked polyethers as media for ionic conduction, British Polymer Journal, 253-268 (1998).

[14] Rajiv Kumar, J.P.S., S.S. Sekhon, FTIR study of ion dissociation in PMMA based gel electrolytes containing ammonium triflate: Role of dielectric constant of solvent, European Polymer Journal, 27182725 (2005) https://doi.org/10.1016/j.eurpolymj.2005.05.010

[15] Nakamoto, K., Infrared and raman spectra of inorganic and coordination compounds, Part A: Theory and applications in inorganic chemistry, John Wiley \& Sons (2009). https://doi.org/10.1002/9780470405840

[16] Phan Trung Nghia, Yoshimasa Yamamoto, Warunee Klinklai, Takayuki Saito, Seiichi Kawahara, Removal of proteins from natural rubber with urea and its application to continuous processes, Journal of Applied Polymer Science, pp. 2329-2332, (2008). https://doi.org/10.1002/app.27236 